\title{
Coix lacryma-jobi Oil
}

National Cancer Institute

\section{Source}

National Cancer Institute. Coix lacryma-jobi Oil. NCI Thesaurus. Code C107294.

The oil extracted from the seeds of Coix lacryma-jobi. Coix lacryma-jobi oil is used primarily in skincare preparations. 